\title{
Bradykinin-related peptides up-regulate the expression of kinin B1 and $B 2$ receptor genes in human promonocytic cell line U937
}

\author{
Ibeth Guevara-Lora ${ }^{\bowtie}$, Magdalena Florkowska and Andrzej Kozik \\ Faculty of Biochemistry, Biophysics and Biotechnology, Jagiellonian University, Kraków, Poland
}

Received: 17 June, 20009; revised: 03 September, 2009; accepted: 07 September, 2009

available on-line: 14 September, 2009

\begin{abstract}
Kinins, universal mediators of inflammation, are recognized by two kinds of receptors, B1 and B2, which have been found to be expressed in numerous cell types of several species. However, the knowledge of the regulation of these receptors in leukocytes is still not satisfactory. In the current work, we have demonstrated a constitutive production of B2 receptor mRNA in the human promonocyte U937 cells and its two-fold augmentation after cell differentiation with retinoic acid and phorbol ester. Bradykinin and des-Arg ${ }^{10}-k_{a l l i d i n}$ induced the expression of both $\mathrm{B} 2$ and B1 receptors in cells before and after differentiation. Generally, the undifferentiated cells were more susceptible to bradykinin-dependent induction of kinin receptors (increases by approximately $250 \%$ and $200 \%$ for B2 and B1 receptors, respectively). The induction, by approx. $200 \%$, of $\mathrm{B} 1$ receptor by des- $\mathrm{Arg}^{10}$-kallidin was detected on both mRNA and protein levels. In addition, an unexpected strong induction of B2 receptor by this compound was observed in the retinoic acidand phorbol ester-differentiated cells (by $150 \%$ and $200 \%$, respectively) that suggests a possible autoregulation of kinin receptors by own agonists during the inflammatory state. On the other hand, a strong enhancement of the expression of both receptors by interleukin $1 \beta$, especially in the phorbol ester-differentiated cells, indicates the involvement of kinin receptors in the propagation of the inflammatory processes.
\end{abstract}

Keywords: kinins, kinin receptors, macrophage, cytokine, inflammation

\section{INTRODUCTION}

Inflammation occurs as a cellular response to infection or tissue injury. During the inflammatory processes the immune system engages several cells, such as macrophages, neutrophils, dendritic cells and natural killer cells, to eliminate microbes or irritants and to potentiate tissue repair. Kinins, shortlived peptides produced from kininogens, are known as important mediators of inflammation which can modulate the majority of events observed during inflammation, including vasodilatation, increased vascular permeability or pain (Kozik et al., 1998; Calixto et al., 2000; Cassim et al., 2002; Imamura et al., 2002; Joseph \& Kaplan, 2005). Kinins, bradykinin (BK) and kallidin (KD), are generated from kininogens by kal- likreins in plasma or in peripheral tissues (Bhoola et al., 1992; Joseph \& Kaplan, 2005). Once formed, these peptides can be quickly degraded by numerous peptidases, called kininases. Kinin-related peptides are recognized by two distinct types of G-coupled receptors: B1 (B1R) and B2 (B2R) (Bhoola et al., 1992; Leeb-Lundberg et al., 2005). The latter is specific for full-length kinins (BK and KD) whereas the B1R shows a high affinity for active kinin metabolites: des-Arg ${ }^{10}$-kallidin (DAKD) and des-Arg'-bradykinin. These receptors differ not only in the pharmacological agonist profile but also in the type and regulation of expression. The B2R is constitutively expressed in the majority of healthy tissues and can be regulated mainly by desensitization, internalization and resensitization. In contrast, B1R is generally induc-

Corresponding author: Ibeth Guevara-Lora, Faculty of Biochemistry, Biophysics and Biotechnology, Jagiellonian University, Gronostajowa 7, 30-387 Kraków, Poland; tel.: (48) 12664 6544; fax: (48) 12664 6902; e-mail: ibeth.guevara-lora@uj.edu.pl Abbreviations: BK, bradykinin; B1R, receptor B1; B2R, receptor B2; DAKD, des-Arg ${ }^{10}$-kallidin; GAPDH, glyceraldehyde3-phosphate dehydrogenase; IL-1 $\beta$, interleukin $1 \beta$; KD, kallidin; PMA, phorbol 12-myristate-13-acetate; RA, retinoic acid. 
ible and is overexpressed in injured tissues during several pathologies including inflammation (Bhoola et al., 1992; Marceau et al., 1998; Leeb-Lundberg et al., 2005). The induction of B1R expression is regulated mainly by cytokines, e.g. interleukin-1 $\beta$ (IL-1 $\beta$ ) or tumor necrosis factor alpha (TNF- $\alpha$ ) (Haddad et al., 2000; Phagoo et al., 2001).

Due to the enhanced kinin occurrence in many disease states, the expression of kinin receptors and its regulation have been widely investigated in diverse types of cells, mainly in those involved in the vascular system, such as endothelial cells, smooth muscle cells and various blood cells (Mathis et al., 1996; Bockmann \& Paegelow, 2000; Ehrenfeld et al., 2006; McLean et al., 2000). Taking into consideration the involvement of kinins in inflammatory responses, many researchers have focused their interest on the effects of these peptides directly in leukocytes, mainly in neutrophils (Rajasekariah et al., 1997; Bockmann \& Paegelow, 2000; Ehrenfeld et al., 2006; Bertram et al., 2007). These observations concern the cellular responses, such as the increase of intracellular $\mathrm{Ca}^{2+}$, chemotaxis or superoxide radical production (Bockmann et al., 1992; Bockmann \& Paegelow, 1995; Ehrenfeld et al., 2006; Bertram et al., 2007). However, knowledge of kinin receptor expression and regulation in leukocytes is not complete. In addition, in the case of mononuclear blood cells such as monocytes and macrophages, these observations are limited and difficult to interpret due to a high heterogeneity of these cells. They form a dynamic population of cells that can appear on several stages of differentiation and maturation and can be activated to diverse degrees with changes in their receptor expression and functional response (Rutherford et al., 1993). In this regard, in this study we chose the human promonocytic cell line U937 for kinin receptor analysis. At resting state, this cell line presents a monoblastic morphology and histochemical profile similar to the monocytic lineage (Harris \& Ralph, 1985). The U937 cells are assumed to be a good model for immune response investigation (Harris \& Ralph, 1985; Cavender et al., 1991) and can be differentiated into monocyte/macrophage stage with agents such as retinoic acid (RA) or phorbol 12-myristate-13-acetate (PMA). The majority of studies on kinin receptor expression in mononuclear cells has been performed in differentiated cells (e.g. peritoneal, alveolar and foamy macrophages, or microglia) from different species (Bockmann \& Paegelow, 2000) while in human monocytes only a weak expression of B2R has been demonstrated and B1R expression has not been investigated at all.

Taking into consideration our recent findings of the binding of kinin progenitors by the U937 cell line (Barbasz et al., 2008), in this work we used these cells, undifferentiated or after differentiation with RA or PMA, as a model system to study the changes of kinin-receptor expression caused by BK and DAKD, the strongest agonists of B2R and B1R, respectively. The mediatory role of kinins in several pro-inflammatory processes has been confirmed, therefore in this work we also analyzed the regulation of these receptors by one of the major cytokines, IL-1 $\beta$. Interestingly, the kinin receptors have been recognized as drug targets (Leeb-Lundberg et al., 2005; Labudda et al., 2007). Therefore, our observations, indicating an up-regulation of kinin receptors by agonists and IL-1 $\beta$, could be important in the field of drug development for several pathophysiological events related to inflammation.

\section{MATERIALS AND METHODS}

Materials. Bovine serum albumin (BSA) was obtained from Amresco (USA), DAKD from BaChem (Germany), captopril and $o$-phenantroline from Fluka (Switzerland), fetal bovine serum (FBS) from Gibco (USA), and RPMI medium, phosphate buffered saline (PBS), antibiotics and antimycotics from PAA (Austria). Bacitracin, bradykinin, IL-1 $\beta$, PMA, and RA were purchased from Sigma (USA). Other chemical reagents were supplied by POCh (Poland).

Cell culture and differentiation. The U937 cells were cultured in Hepes-stabilized RPMI medium supplemented with $10 \%$ FBS, $100 \mathrm{U} / \mathrm{ml}$ penicillin, $0.1 \mathrm{mg} / \mathrm{ml}$ streptomycin and $2.5 \mu \mathrm{g} / \mathrm{ml} \mathrm{am-}$ photericin $\mathrm{B}$ for 5 days in a humidified atmosphere containing $5 \% \mathrm{CO}_{2}$ at $37^{\circ} \mathrm{C}$. For differentiation, the cells were suspended in $2 \%$ FBS medium with $1 \mu \mathrm{M}$ RA or $25 \mathrm{nM}$ PMA for 1 day. Next, the cells were incubated for 3 days in $2 \%$ FBS medium before the experiments were carried out.

Determination of the mRNA expression for selected genes. Cells $\left(2.5 \times 10^{6}\right)$, either undifferentiated or after differentiation, were incubated with BK or DADK at $1 \mathrm{nM}$ concentration for up to $5 \mathrm{~h}$ in RPMI medium supplemented with kininase inhibitors $(20 \mu \mathrm{M}$ captopril, $100 \mu \mathrm{M}$ o-phenantroline and $500 \mu \mathrm{M}$ bacitracin). Similar experiments were performed with $10 \mathrm{ng} / \mathrm{ml}$ IL- $1 \beta$. After incubation, the total RNA was isolated from cells with Total RNA Isolation System (Promega, USA). The B1R, B2R and IL-1 $\beta$ gene expression was analyzed with a two step RT-PCR procedure. The GAPDH mRNA expression was measured in every sample for a semiquantitative analysis. First, the cDNA was synthesized with Super Script II Rnase H-Reverse Transcriptase (Invitrogen, USA) according to the manufacturer's instruction and with $10 \mu \mathrm{M}$ dT oligomers. Next, the amplification of cDNA $(2 \mu \mathrm{l})$ by PCR was performed in a $25 \mu$ reaction mixture with Taq polymerase (Finnzymes, Finland), $0.1 \mathrm{mM}$ dNTP (Fermentas, 
Canada) and $0.2 \mu \mathrm{M}$ specific primers. The primer pair sequences were: $5^{\prime}$ ctttcctatgggatgaagatat $3^{\prime}$ and $5^{\prime}$ ttcttattccaggtgcaagcag $3^{\prime}$ for B1R, $5^{\prime}$ cacggtgctagtcctggttgtgct $3^{\prime}$ and $5^{\prime}$ aggtccgcagtgtgcccatg $3^{\prime}$ for B2R, $5^{\prime}$ gatgtctggtccatatgaactg $3^{\prime}$ and $5^{\prime}$ ttgggatctacactctccagc $3^{\prime}$ for IL-1 $\beta$, and $5^{\prime}$ tctagacggcaggtcaggtccacc $3^{\prime}$ and $5^{\prime}$ ccacccatggcaaattccatggca $3^{\prime}$ for GAPDH (Oligo.pl, Poland). The annealing temperature for B1R, $\mathrm{B} 2 \mathrm{R}, \mathrm{IL}-1 \beta$ and GADPH was $62^{\circ} \mathrm{C}, 71^{\circ} \mathrm{C}, 62^{\circ} \mathrm{C}$ and $70^{\circ} \mathrm{C}$, respectively. The PCR conditions included an initial denaturation step of $5 \mathrm{~min}$ at $95^{\circ} \mathrm{C}$, followed by 35 cycles $\left(30 \mathrm{~s}\right.$ denaturation at $95^{\circ} \mathrm{C}, 30 \mathrm{~s}$ of primer annealing at the appropriate temperature, $30 \mathrm{~s}$ at $72^{\circ} \mathrm{C}$ ) and one cycle of $10 \mathrm{~min}$ for cDNA extension at $72^{\circ} \mathrm{C}$. The PCR products for B1R, B2R, IL- $1 \beta$ and GAPDH gene, resolved on $1 \%$ agarose gels containing ethidium bromide for ultraviolet detection, were $214 \mathrm{bp}, 314 \mathrm{bp}, 210 \mathrm{bp}$ and $598 \mathrm{bp}$, respectively.

Analysis of B1R protein by immunocytochemistry. PMA-differentiated cells $\left(2 \times 10^{5}\right)$, after stimulation with $1 \mathrm{nM}$ BK or DAKD and $10 \mathrm{ng} / \mathrm{ml}$ IL-1 $\beta$ or with the peptides in the presence IL-1 $\beta$, were attached to a glass coverslide by cytospin. Next, the cells were fixed with $100 \%$ cold methanol and incubated with 1\% BSA. After 40-min blocking, the cells were incubated overnight at $4^{\circ} \mathrm{C}$ with rabbit anti-human B1 receptor antibody (Abcam, UK) at 1:50 dilution in PBS supplemented with $0.5 \%$ BSA. After 3-fold washing, the fixed cells were treated with a secondary antibody, FITC-labeled goat antirabbit IgG (Abcam, UK) at 1:250 dilution in PBS for $1 \mathrm{~h}$ at room temp. in the dark. The coverslide mounting with microscope slides was preceded by extensive washing with PBS and distilled water. The antibody-labeled cells were analyzed with epifluorescence DM IRE2 microscope (Leica, Germany). A negative control probe was prepared omitting the first antibody incubation.

Quantitative image analysis. For a semiquantitative analysis of RT-PCR, the gel-band intensity of the PCR products was measured by densitometry with Fluor-S Multilmager (BioRad Laboratories, USA) and Quantity One software. The intensity of the PCR product band of every investigated probe was divided by the intensity of GAPDH PCR product band. The results are presented as the percentage of the cell response to stimulation as compared with unstimulated cells.

The fluorescent intensity of B1R-bound FITClabeled antibody in the studied samples was quantified using ImageJ software. The measured area was selected with "brightness slicing" procedure with a constant lower threshold value. The mean area was measured as the sum of the gray values of all pixels in the selection and then divided by the number of pixels. The mean area value for the negative control was subtracted from the positively labeled slides.
The resulting value represents the net signal intensity derived from specific immunolabeled probes. The intensities of three different images on each slide were averaged.

Statistical analysis. All values were presented as means \pm S.D. of at least three experiments. Data were analyzed by Student's $t$-test and the differences were judged to be significant at $P<0.05$.

\section{RESULTS}

The U937 cells were analyzed for basal B2R and B1R mRNA production before and after differentiation with RA or PMA. According to previous reports, the obtained monocyte-like cells after RA treatment were non-adherent and showed only insignificant proliferation while phorbol esters caused changes in adherence and induced a macrophage-like morphology (Honma et al., 1980; Harris \& Ralph, 1985). In this study, the undifferentiated cells unquestionably showed a clear expression of the B2R gene (Fig. 1) that was enhanced by RA or PMA treatment by 2- and 1.7fold, respectively. The B1R expression was lower than that of B2R. The incubation with RA augmented the production of mRNA of this receptor (two-fold) while no significant effect of PMA on B1R gene expression was observed.

The mean value of kinins in normal human plasma is reported to be in the picomolar range (Blais et al., 2000). We chose $1 \mathrm{nM}$ kinin concentration to analyze their effects on the regulation of kinin receptor expression, assuming that the applied concentration approaches the pathological levels of these inflammatory mediators. A clear, strong upregulatory effect of BK on kinin receptor genes was observed (Fig. 2). In the undifferentiated U937 cells, BK caused a time-dependent increase in mRNA expression of the B2R with a maximum after $3 \mathrm{~h}$ (above 250\%) (Fig. 2A). After 5-h incubation with this kinin, the amount of B2R mRNA decreased nearly to the initial value. A similar but faster effect was observed for the differentiated cells, with a maximal cell response after two hours (Fig. 2B). The RA-differentiated cells showed a somewhat stronger response as compared to PMA-treated cells (by $230 \%$ versus $160 \%$ ) and these increases were significant compared to unstimulated cells. BK was able to stimulate not only the increase of B2R mRNA but also the mRNA of the second kinin receptor, B1R. This effect was also time-dependent and the maximal increase was obtained after 2-h incubation. In general, the amount of induced mRNA for B1R was lower as compared with $\mathrm{B} 2 \mathrm{R}$ expression. The highest cell response was observed in undifferentiated cells and did not exceed $200 \%$ while the increase observed in differen- 
A
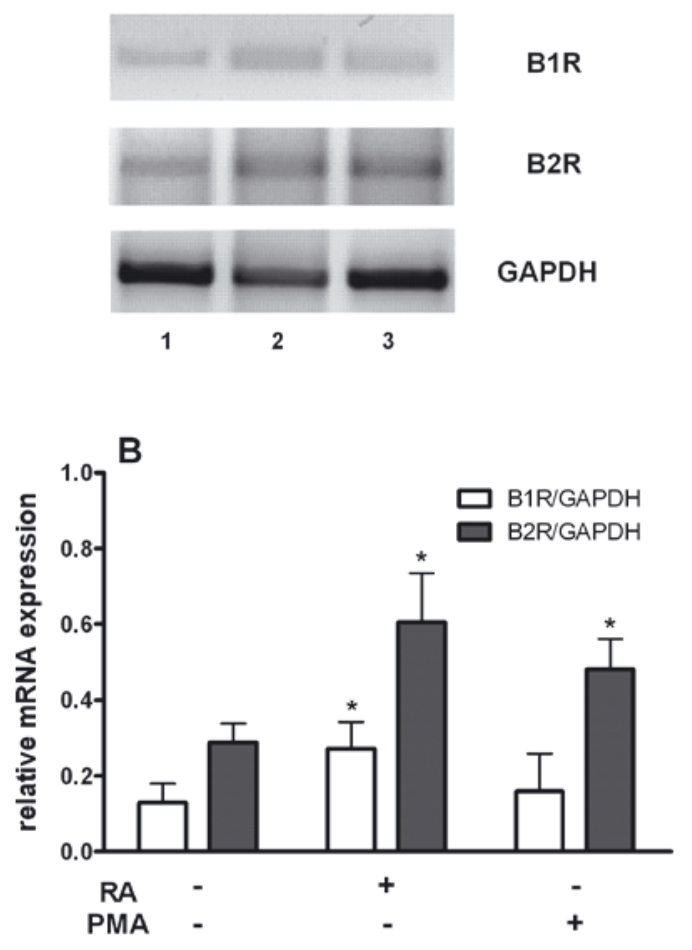

Figure 1. The effect of RA- or PMA-induced differentiation of U937 cells on the kinin receptor gene expression. The total RNA was isolated in cells before and after differentiation with $1 \mu \mathrm{M}$ RA or $25 \mathrm{nM}$ PMA. The expression of B1R, B2R and GAPDH genes was analyzed by RT-PCR and the relative mRNA expression of kinin receptors was calculated as described under Materials and Methods. (A) The PCR products separated in agarose gel electrophoresis for undifferentiated cells (lane 1), after differentiation with RA (lane 2) or PMA (lane 3). (B) The calculated relative mRNA for kinin receptors in U937 cells before and after differentiation. Data points represent mean values \pm standard deviation from at least three independent experiments. ${ }^{*} P<0.05$ vs. undifferentiated cells.

tiated cells was not significant in comparison with unstimulated cells (Fig. 2C).

The second agonist used, DAKD, exhibits a high affinity to $\mathrm{B} 1$ receptor. The analysis of the results obtained from the incubation of undifferentiated cells with DAKD indicates a time-dependent up-regulation of B1R mRNA that achieved the maximal cell response at $2 \mathrm{~h}$ with a value above $200 \%$ as compared to unstimulated cells (Fig. 3A). A similar effect was observed in RA-differentiated cells after stimulation with $1 \mathrm{nM}$ DAKD (Fig. 3A). The results obtained for PMA-differentiated cells, stimulated with $1 \mathrm{nM}$ DAKD, were not consistent; the time of maximal response was highly variable between separate experiments (from 1 to $4 \mathrm{~h}$ ) but in every case a slight up-regulation for B1R was observed that did not exceed $150 \%$ of the cell response as compared to unstimulated cells (not
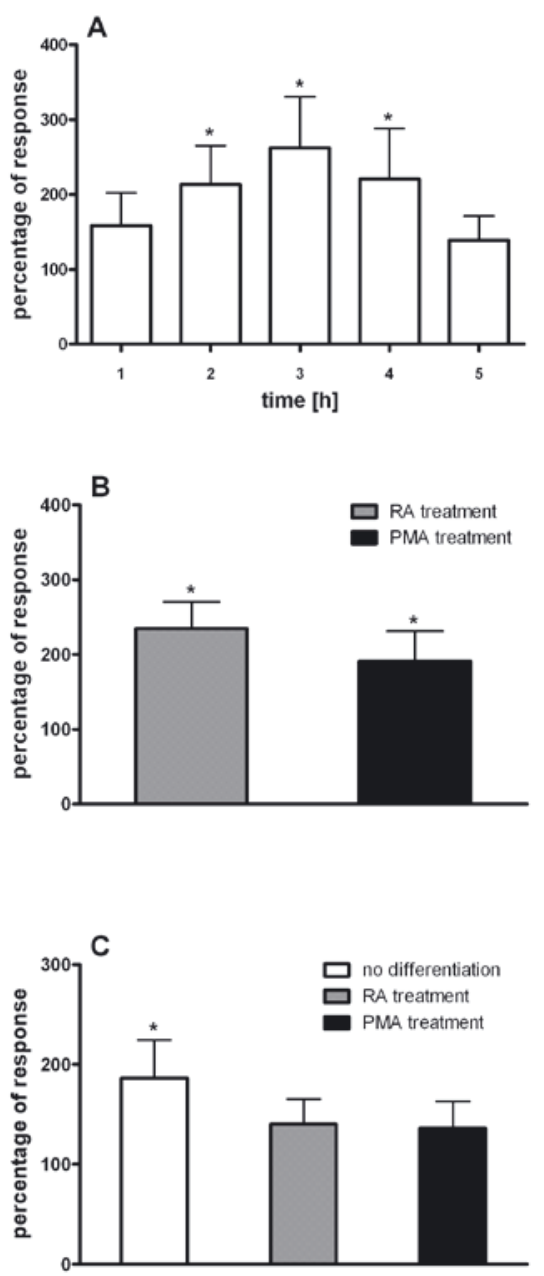

Figure 2. The induction of kinin receptor mRNA in U937 cells by bradykinin.

Cells after differentiation with $1 \mu \mathrm{M}$ RA or $25 \mathrm{nM}$ PMA or without differentiation were incubated with $1 \mathrm{nM}$ BK. After RNA isolation the gene expression of B1R, B2R and GAPDH was analyzed by RT-PCR in separate samples every hour. The figures present the time dependent expression of B2R gene in undifferentiated cells (A), the relative B2R (B) and B1R (C) gene expression at the maximal cell response obtained after 2-hour incubation with BK as compared to unstimulated cells. The percentage of the response was determined as described under Materials and Methods and expressed in relation to the values obtained for unstimulated cells (assumed to be 100\%; not shown). Values are mean \pm standard deviation from three independent experiments. ${ }^{*} P<0.05$ vs. unstimulated cells.

shown). A more interesting observation was related to the augmentation of the B2R mRNA expression in PMA-differentiated cells by $1 \mathrm{nM}$ DAKD. This increase achieved the maximal value (220\%) after $2 \mathrm{~h}$ of incubation (Fig. 3B). Thereafter, the amount of B2R mRNA strongly decreased (not shown). This effect was attenuated in RA-treated cells, with the augmentation of mRNA expression by approx. $150 \%$ above the unstimulated cell response value (Fig. 3B). The undifferentiated cells did not 

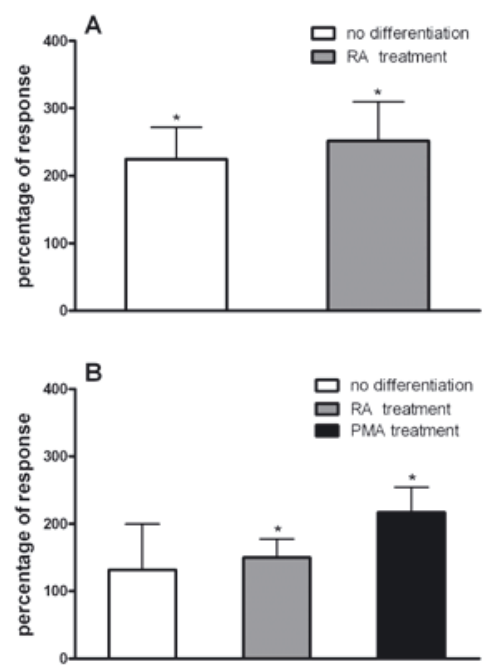

Figure 3. The induction of kinin receptor mRNA in U937 cells by DAKD.

Cells after RA- or PMA-differentiation or without differentiation were stimulated with $1 \mathrm{nM}$ DAKD. After RNA isolation the gene expression of $B 1 R, B 2 R$ and GAPDH was analyzed by RT-PCR in separate samples every hour. The figures present the B1R (A) and B2R (B) mRNA expression at the maximal cell response achieved after $2 \mathrm{~h}$ in comparison to unstimulated cells. The percentage of the response was determined as described under Materials and Methods and expressed in relation to unstimulated cells (assumed to be 100\%; not shown). Data points are mean \pm standard deviation from three independent experiments. ${ }^{*} P<0.05$ vs. unstimulated cells.

show significant changes in B2R mRNA upon $1 \mathrm{nM}$ DAKD incubation (Fig. 3B).

The regulation of kinin receptor expression by IL-1 $\beta$ was also analyzed. The effect of IL- $1 \beta$ on the augmentation of B2R mRNA was undisputable (Fig. 4A). The response to cytokine was detected already from the first $30 \mathrm{~min}$ of incubation and the maximum was achieved after 1-hour incubation. It was more intensive for RA- and PMA-differentiated cells (2-fold and 4-fold, respectively) as compared to unstimulated cells. The B2R up-regulation was prolonged even after $5 \mathrm{~h}$ of cytokine incubation with PMA-treated cells (not shown), when the percentage of induced mRNA is still high $(200 \%$ in comparison to uninduced cells). On the other hand, a strong induction of B1R gene was observed when PMA- and RA-differentiated cells were stimulated with IL-1 $\beta$ ( $370 \%$ and $140 \%$, respectively) (Fig. $4 \mathrm{~A}$ ). The maximal response occurred after $1 \mathrm{~h}$ of stimulation and, similarly to the B2R receptor induction, this effect was only moderately decreased after $5 \mathrm{~h}$. No significant change in the mRNA level of this receptor was observed in undifferentiated cells after cytokine stimulation as compared to unstimulated cells.

The significant influence of IL- $1 \beta$ on mRNA augmentation of kinin receptors in U937 cells prompted us to investigate the effect of $\mathrm{BK}$ and DAKD on the induction of this cytokine. The kinin
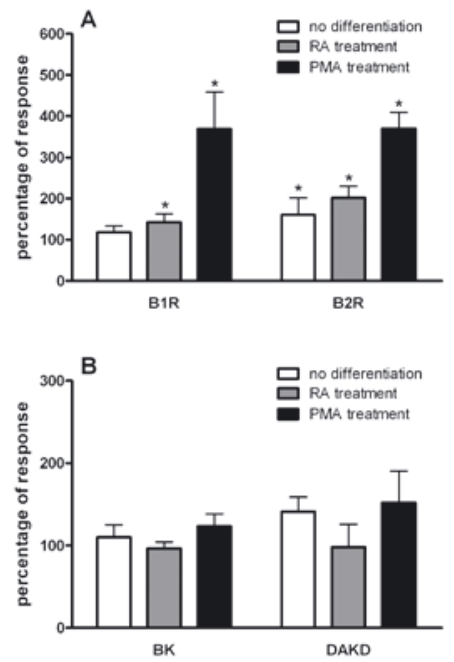

Figure 4. The IL-1 $\beta$ role in the mRNA expression of kinin receptors.

(A) Cells undifferentiated and after RA- or PMA differentiation were incubated with $10 \mathrm{ng} / \mathrm{ml} \mathrm{IL}-1 \beta$. After RNA isolation, the B1R, B2R and GAPDH expression was analyzed by RT-PCR. The figure shows the maximal cell response achieved after 30-minute incubation for B2R and after 1-hour incubation for B1R. (B) Cells were incubated with BK or DAKD at $1 \mathrm{nM}$ concentration and the expression of IL-1 $\beta$ and GAPDH mRNA was measured by RTPCR. The figure presents the maximal increase of cytokine gene expression reached after 1-hour or 2-hour incubation for differentiated or undifferentiated cells, respectively. The percentage of the response was determined as described under Materials and Methods in relation to unstimulated cells (assumed to be 100\%; not shown). Data are presented as means \pm standard deviation from three independent experiments. ${ }^{*} P<0.05$ vs. unstimulated cells.

effect on the regulation of cytokine expression in U937 cells was poor (Fig. 4B). The kallidin metabolite, DAKD, seemed to be more effective in IL-1 $\beta$ expression in these cells. A weak increase was only observed in PMA-treated cells after stimulation with both $1 \mathrm{nM}$ BK and $1 \mathrm{nM}$ DAKD (by 130\% and 150\%, respectively).

The expression of B1R, the inducible receptor, was also investigated at the protein level by immunocytochemistry. Figure 5A shows the immunocytochemical images obtained after incubation of the PMA-treated cells with BK, DAKD and IL-1ß. The fluorescence signal derived from FITC-labeled antibody was more pronounced in stimulated cells compared to control cells. The quantitative analysis of the obtained images is presented in Fig. 5B. Kinins and IL- $1 \beta$, or these peptides in the presence of IL-1 $\beta$, induced an increase in B1R protein on the PMA-treated cell surface. The level of this protein expression is similar in the studied samples, with the value 2 to 2.5 fold higher than that on the surface of unstimulated cells. The major production of B1R protein was observed for the incubation with DAKD and cytokine (above 2-fold). BK was also able to in- 
A

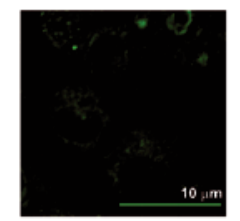

Control

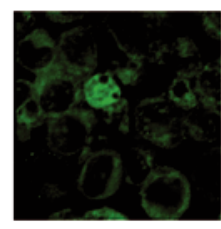

IL $1 \beta$

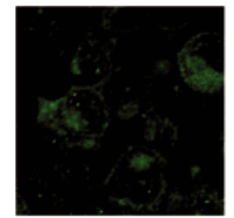

BK

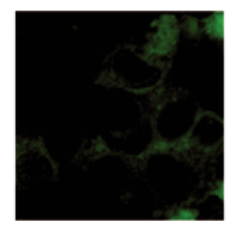

IL $1 \beta+B K$

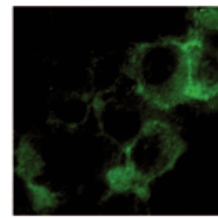

DAKD

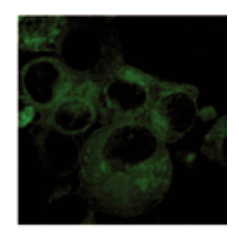

IL $1 \beta+$ DAKD

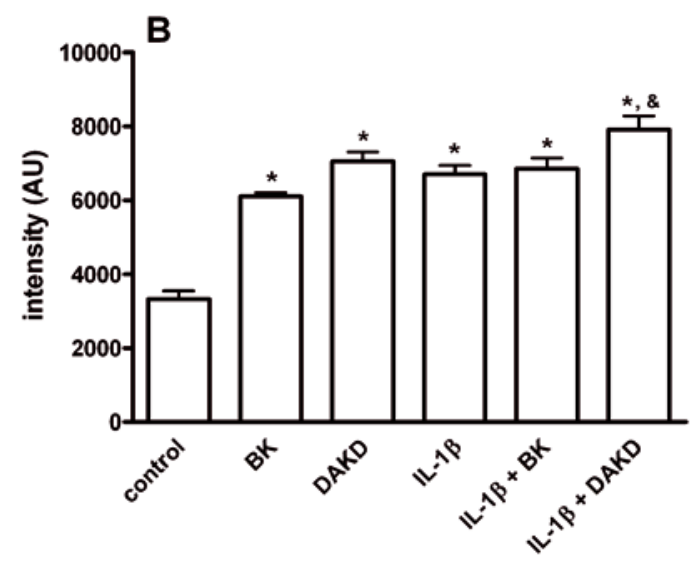

Figure 5. The induction of B1R protein expression on PMA-differentiated U937 cells by kinins and IL-1 $\beta$. The cells were incubated for $6 \mathrm{~h}$ with $1 \mathrm{nM} B K, 1 \mathrm{nM}$ DAKD and $10 \mathrm{ng} / \mathrm{ml} \mathrm{IL-1 \beta}$ or with the peptides in the presence of IL-1 $\beta$. A. Visualization of B1R receptor after cell stimulation. B. The fluorescence intensity was determined as described under Materials and Methods. AU, arbitrary units. Data are presented as mean \pm standard deviation from three independent experiments. ${ }^{*} P<0.05$ vs. control; \& $P<0.05$ vs. cells stimulated with IL-1 $\beta$.

duce the B1R protein expression, though to a lesser extent as compared to the DAKD effect. In general, it seemed that the coincubation of kinins with IL- $1 \beta$ enhanced the increase in the amount of B1 receptors in investigated cells.

\section{DISCUSSION}

Mononuclear blood cells such as monocytes and macrophages exist in distinct stages of differentiation and maturation. The U937 cell line, selected as the model for this study, showed diverse stages of differentiation like in mononuclear blood cells. After RA treatment we obtained non-adherent and non-prolifering cells, resembling the monocyte state while after stimulation with PMA the cells showed a higher adhesive capability like macrophages. The basal kinin receptor in these cells varied significantly before and after differentiation. We found a constitutive B2R expression in undifferentiated cells, while B1R expression, though visible, was very low in the majority of the analyzed samples and a possible induction during sample processing cannot be excluded (Fig. 1). The effect of the differentiation agents on the B1R and B2R receptor expression allow us to suggest that cell maturation is accompanied by an overexpression of these receptors, especially of B2R. The RA- and PMA-differentiation of U937 cells is associated with the increase of reactive oxygen species and cytokines, augmented enzymatic activity and changes in the cell membrane (Harris \& Ralph, 1985), the effects which are likely to result in activation of the kinin receptor pathway.

Previous studies have demonstrated kinin binding to macrophages or the physiological response of these cells to kinins but the kinin receptor expression in monocytes or macrophages had not been extensively investigated. In this study, we focused on the investigation of the level of kinin receptors after agonist treatment in the monocyte/macrophage-liked cells. Our results clearly showed the induction of B2R mRNA expression in U937 cells by BK, independently of its differentiated or undifferentiated state (Figs. 2A and 2B). In comparison to differentiated cells, the resting ones slowly but strongly produced B2R mRNA in response to BK. This can be related to the lower initial level of the receptor expression in undifferentiated cells. The lower response of macrophage-like cells may be related to the relatively high heterogeneity of these cells displaying diverse differentiation or activation stages, including membrane integrin expression and phagocytosis after phorbol ester treatment (Hamada \& Utiyama, 2005). A stimulation of B1R receptor expression by its own agonist was observed in human fibroblasts (Schanstra et al., 1998; Phagoo et al., 2001). Likewise, our study showed an increase of B1R mRNA in U937 cells after incubation with DAKD (Fig. 3A). The equivocal effect of this metabolite in PMA-treated cells may be also attributed to their high heterogeneity. Generally, we demonstrated that in monocyte- and macrophage-like cells, the regulation of $\mathrm{B} 2 \mathrm{R}$ and $\mathrm{B} 1 \mathrm{R}$ at the mRNA level by its own agonist is possible. Normally, B2R are regulated at the protein levels by internalizing together with the agonist molecule and by resensitization (Leeb-Lundberg et al., 2005). The B1R are inducible and their expression on the cell surface may decrease. In these situations, the de novo synthesis of the receptors after mRNA up-regulation by own agonists may be important in the prolonged inflammatory state. 
The autoregulation of kinin receptors by kinins was reported for the first time in human lung fibroblasts (Phagoo et al., 1999). These authors demonstrated an induction of B1R gene with simultaneous decrease in $\mathrm{B} 2 \mathrm{R}$ expression by kinins, especially in the presence of cytokines. In our study, the U937 cell line also showed the B1R regulation by BK (Figs. 2 and 5) but the involvement of IL-1 $\beta$ in this regulation is not clear (Fig. 4B). Only the PMA-differentiated cells showed a relatively low expression of the cytokine mRNA. In this work, in contrast to previous reports (Phagoo et al., 2000), an unexpected stimulatory effect of DAKD on B2R expression in PMA-treated U937 cells was detected (Fig. 3B). $\mathrm{B} 2 \mathrm{R}$ is constitutively expressed, but several potential binding sites for transcription factors, such as NF- $\mathrm{kB}$, have been identified on the gene promoter (Pesquero et al., 1996). Moreover, the induction of NF- $\mathrm{KB}$ by DAKD was proved in human IMR-90 cells (Schanstra et al., 1998). Therefore, it can be presumed that B1R agonist could activate signal pathways, which quickly and intensively enhance the B2R gene transcription. The B2R gene induction by DAKD could play an important role in the mechanism of autoregulation of kinin receptors, especially in the propagation of the inflammatory processes.

Because the regulation of kinin receptor expression by cytokines in several cells has been observed and the mononuclear cells are able to secrete these mediators, we proposed a contribution of cytokines to the regulation of kinin receptor in U937 cells. We selected IL-1 $\beta$, a cytokine of the acute phase inflammation state which is secreted by macrophages (Harris \& Ralph, 1985; Rutherford et al., 1993) to test this hypothesis. The majority of the papers related to the synergistic effect of IL- $1 \beta$ and kinins on leukocytes are concerned with free radical production, enhanced calcium transport or agonist binding by these cells (Bockmann et al., 1992; Bockmann \& Paegelow, 1995). In this study we analyzed the mRNA expression of B1R and B2R upon IL-1 $\beta$ stimulation in U937 cell differentiated to monocytes or macrophages and in undifferentiated cells. As expected, we found that this cytokine caused a strong increase in mRNA of B2R (Fig. 4A). The obtained results showed an effective induction of B2R mRNA expression, with a positive regulation noted even in undifferentiated cells (by about 170\%), as well as in RA- and PMA-treated cells (by about $200 \%$ and $400 \%$, respectively). The gene regulation of B1R by IL-1 $\beta$ was already demonstrated in a murine alveolar macrophage cell line (Tsukagoshi et al., 1999). Our results also showed an up-regulation of B1R mRNA after IL-1 $\beta$ stimulation but only in PMA-differentiated U937 cells. Probably, the cells at the differentiated stage after PMA treatment could be more sensible to cytokine action. Summing up, although we did not observe a significant increase of mRNA expression of IL-1 $\beta$ induced by kinin-related peptides, the participation of this cytokine in the kinin receptor expression was confirmed (Fig. 4A).

The regulation of $\mathrm{B} 1 \mathrm{R}$ by $\mathrm{BK}, \mathrm{DAKD}$, and IL-1 $\beta$ was confirmed at the protein level (Fig. 5). A pronounced effect was obtained for the specific agonist for B1R, DAKD alone or with the peptides in the presence of IL-1 $\beta$. This observation validates the results obtained at the gene level, corroborating the hypothesis that IL-1 $\beta$ can enhance the B1R expression. Taken together, these results showed the regulation of kinin receptors by kinins and their metabolites as well as by cytokines, such as IL- $1 \beta$. Thus, the presence of these substances in injured tissues may prolong the kinin effects by the enhancement of their receptors.

In summary, we demonstrated the constitutive expression of B2 receptors on promonocytic U937 cell line as well as after differentiation to monocyte/ macrophage-like cells. The specific agonists were able to induce the expression of both kinin receptors. In addition, an inflammation mediator, such as IL-1 $\beta$ can regulate the mRNA of both receptors and enhance their expression. Therefore kinins, through their receptors, can play an essential role in the immune response. The enhancement of kinin receptor expression by IL-1 $\beta$ can contribute to prolonging the inflammation processes leading to development of the chronic state. Thus, pharmacological manipulation of the B1 and B2 receptors opens new ways to the treatment of a wide range of diseases associated with the inflammatory responses.

\section{Acknowledgements}

The authors thank Dr. Jolanta Sroka for the access to the epifluorescence microscope and for her helpful technical suggestions.

This work has been supported by grant No. N301 067 31/2018 from the Ministry of Science and Higher Education (Poland).

\section{REFERENCES}

Barbasz A, Guevara-Lora I, Rapala-Kozik M, Kozik A (2008) Kininogen binding to the surfaces of macrophages. Int Immunopharm 8: 211-216.

Bertram CM, Baltic S, Misso NL, Bhoola KD, Foster PS, Thompsom PJ, Fogel-Petrovic M (2007) Expression of kinin B1 and B2 receptors in immature monocyte-derived dendritic cells and bradykinin-mediated increase in intracellular $\mathrm{Ca}^{2+}$ and cell migration. J Leukoc Biol 81: 1445-1454.

Bhoola KD, Figueroa CD, Worthy K (1992) Bioregulation of kinins: kallikreins, kininogens, and kininases. Pharmacol Rev 44: 1-80. 
Blais Ch Jr., Marceau F, Roleau J-L, Adam A (2000) The kallikrein-kininogen-kinin system: lessons for the quantification of endogenous kinins. Peptide 21: 1903-1940.

Bockmann S, Mohrdieck K, Schmidt H, Zundorf G, Paegelow I (1992) Differential sensitivity of macrophages to bradykinin. Naunyn-Schmiedeberg's Arch Pharmacol 357: 151-158.

Bockmann S, Paegelow I (1995) Bradykinin receptors and signal transduction pathways in peritoneal guinea pig macrophages. Eur J Pharmacol 291: 159-165.

Böckmann S, Paegelow I (2000) Kinins and kinin receptors: importance for the activation of leukocytes. J Leukoc Biol 68: 587-592.

Calixto JB, Cabrini DA, Ferreira J, Campos MM (2000) Kinins in pain and inflammation. Pain 87: 1-5.

Cassim B, Mody G, Bhoola KD (2002) Kallikrein cascade and cytokines in inflamed joints. Pharmacol Ther 94: $1-34$.

Cavender DE, Edelbaum D, Welkovich L (1991) Effects of inflammatory cytokines and phorbol esters on the adhesion of U937 cells, a human monocyte-like cell line, to endothelial cell monolayers and extracellular matrix proteins. J Leukoc Biol 49: 566-578.

Ehrenfeld P, Millan C, Matus CE (2006) Activation of kinin B1 receptors induces chemotaxis of human neutrophils. J Leukoc Biol 8: 117-124.

Haddad El-B, Fox AJ, Rousell J, Burgess G, Mcintyre P, Barnes PJ, Fan Chung K (2000) Post-transcriptional regulation of bradykinin $\mathrm{B} 1$ and $\mathrm{B} 2$ receptor gene expression in human lung fibroblasts by tumor necrosis factor- $\alpha$ : modulation by dexamethasone. Mol Pharmacol 57: 1123-1131.

Hamada K, Utiyama K (2005) Functional cytoplasmic of the Mac-1 integrin receptor on phorbol ester-treated U937 cells. Biochem Biophys Res Commun 335: 858-864.

Harris P, Ralph P (1985) Human leukemic models of myelomonocytic development: a review of the HL-60 and U937 cell lines. J Leukoc Biol 37: 407-422.

Honma Y, Takenaga K, Kasukabe T, Hozumi M (1980) Induction of differentiation of cultured human promyelocytic leukemia cells by retinoids. Biochem Biophys Res Commun 95: 507-512.

Imamura T, Tanase S, Hayashi I, Potempa J, Kozik A, Travis J (2002) Release of a new vascular permeability enhancing peptide from kininogens by human neutrophil elastase. Biochem Biophys Res Commun 294: 423428.

Joseph K, Kaplan AP (2005) Formation of bradykinin: a major contribution to the innate inflammatory response. Adv Immunol 86: 159-208.

Kozik A, Moore RB, Potempa J, Imamura T, Rapala-Kozik M, Travis J (1998) A novel mechanism for bradykinin production at inflammatory sites. Diverse effect of a mixture of neutrophil elastase and mast cell tryptase versus tissue and plasma kallikreins on native and oxidized kininogens. J Biol Chem 273: 33224-33229.
Labudda O, Wierzba T, Sobolewski D, Sleszynska M, Gawinski Ł, Plackova M, Slaninova J, Prahl A (2007) New bradykinin analogues on the N-terminus: effect on rat uterus and blood pressure. Acta Biochim Polon 54: 193-198.

Leeb-Lundberg LMF, Marceau F, Muller-Esterl W, Pettibone DJ, Zuraw BL (2005) International Union of Pharmacology. XLV. Classification of the kinin receptor family: from molecular mechanisms to the pathological consequences. Pharmacol Rev 57: 27-77.

Marceau F, Hess JF, Bachvarov DR (1998) The $B_{1}$ receptors for kinins. Pharmacol Rev 50: 357-386.

Mathis SA, Criscimagna NL, Leeb-Lundberg LMF (1996) B1 and B2 kinin receptors mediate distinct patterns of intracellular $\mathrm{Ca}^{2+}$ signaling in single cultured vascular smooth muscle cells. Mol Pharmacol 50: 128-139.

McLean PG, Perretti M, Ahluwalia A (2000) Kinin B receptors and the cardiovascular system: regulation of expression and function. Cardiovasc Res 45: 194-210.

Pesquero JB, Lindsy CJ, Paiva ACM, Ganten D, Bader M (1996) Transcriptional regulatory elements in the rat bradykinin B2 receptor gene. Immunopharmacology 33: 36-41.

Phagoo SB, Poole S, Leeb-Lundberg LMF (1999) Autoregulation of bradykinin receptors: agonists in the presence of interleukin-1 beta shift the repertoire of receptor subtypes from B2 to B1 in human lung fibroblasts. Mol Pharmacol 56: 325-333.

Phagoo SB, Reddi K, Anderson KD, Leeb-Lundberg LMF, Warburton D (2001) Bradykinin B1 receptor up-regulation by interleukin-1 $\beta$ and B1 agonist occurs through independent and synergistic intracellular signaling mechanisms in human lung fibroblasts. J Pharmacol Exp Ther 298: 77-85.

Rajasekariah P, Warlow RS, Wall RS (1997) High affinity bradykinin binding to human inflammatory cell. Biochem Mol Biol Int 43: 279-290.

Rutherford MS, Witsell A, Schook LB (1993) Mechanism generating functionally heterogeneous macrophages: chaos revisited. I Leukoc Biol 53: 602-618.

Schanstra JP, Bataille E, Castano MEM, Barascud Y, Hirtz C, Pesquero JB, Pecher C, Gauthier F, Girolami JP, Bascands JL (1998) The B1-agonist [des-Arg ${ }^{10}$ ]-kallidin activates transcription factor NF-kappaB and induces homologous up-regulation of the bradykinin $\mathrm{B}_{1}$-receptor in cultured human lung fibroblasts. J Clin Invest 101: 2080-2091.

Tsukagoshi H, Shimizu Y, Horie T, Fukabori Y, Shimizu Y, Iwamae S, Hisada T, Ishizuka T, Iizuka K, Dobashi K, Mori M (1999) Regulation by interleukin-1 $\beta$ of gene expression of bradykinin B1 receptor in MH-S murine alveolar macrophage cell line. Biochem Biophys Res Commun 259: 476-482. 